\title{
On the complexity of radiation models for PV energy production calculation
}

\author{
O. Perpiñan \\ ISOFOTON S.A., Montalban 9, 28014 Madrid, Spain \\ E. Lorenzo \\ Solar Energy Institute, UPM, Ciudad Universitaria, s/n, 28040 Madrid, Spain \\ M. A. Castro \\ Electrical and Computer Engineering Department, UNED, Juan del Rosal, 12, \\ Ciudad Universitaria, 28040 Madrid, Spain \\ R. Eyras \\ ISOFOTON S.A., Montalban 9, 28014 Madrid, Spain
}

\begin{abstract}
Several authors have analysed the changes of the probability density function of the solar radiation with different time resolutions. Some others have approached to study the significance of these changes when produced energy calculations are attempted. We have undertaken different transformations to four Spanish databases in order to clarify the interrelationship between radiation models and produced energy estimations. Our contribution is straightforward: the complexity of a solar radiation model needed for yearly energy calculations, is very low. Twelve values of monthly mean of solar radiation are enough to estimate energy with errors below $3 \%$. Time resolutions better than hourly samples do not improve significantly the result of energy estimations.
\end{abstract}

Key words: Radiation statistics, PV grid-connected systems, Energy calculation, Probabilistic Density Function

Email address: o.perpinan@isofoton.com (O. Perpiñan).

1 ISES Member

Preprint submitted to Elsevier

June 19, 2007 


\section{Introduction}

Available information on solar radiation is given in compact forms: monthly averages of daily horizontal irradiation, Typical Meteorological Year, etc. Obviously, such compactness facilitates engineering practises (sizing, energy production forecast, etc.) but this is not without price, because these compacts forms do not necessarily reproduce all the statistical features of the original solar radiation data sequences. In particular, probabilistic distributions of irradiance are not preserved, so that "the logical question is how these differing distributions affect the energy output of a solar system"(Gansler et al., 1995).

This paper deals with this question when only energy production of a PV grid connected system (PVGCS) is concerned. Then, representativity of a particular solar information form is not related with repeating statistical distributions but with estimating yearly energy output. For that, we have used original solar radiation sequences from several Spanish locations. From them, we have derived different compact information patterns. Then we have calculated the energy output of a PVGCS with all these data structures as different input possibilities and we have compared the corresponding results.

Related literature started in 1960, when Liu and Jordan attempt to describe solar radiation as an stochastic process (Liu and Jordan, 1960). A set of probabilistic distributions for daily values of clearness index were proposed. Since then, several authors have investigated what happens to stochastic behaviour of radiation when time resolution is reduced from daily values to hourly sampling. Here, a dependence with air mass is found, while probabilistic distributions for daily values are independent from locality and day of the year (Aguiar and Collares-Pereira, 1992).

Moreover, if time resolution is reduced to minute sampling, a bimodal behaviour appears, again using air mass influence as the key factor. However,a number of authors conclude that bimodal behaviour becomes more distinct with increasing air mass (Skartveit and Olseth, 1992; Tovar et al., 1998; Suehrcke and McCormick, 1988), while others observe a crescent bimodality with decreasing air mass (Assunçâo et al., 2003; Gansler et al., 1995).

Although most of previous studies state in their introductions that intrahourly variations could lead to inaccurate estimations of energy production, only in Gansler et al. (1995) an attempt of validation is included. A 50 Wp gridconnected PV system is simulated with 1 minute sampled radiation data from San Antonio (USA), concluding that "the difference in hourly electrical energy for this maximum power point tracking system calculated with equation [of percent difference between hourly and 1-minute-samples calculation] is very small". 
Other groups of authors have explicitly tried to analyse energy estimations when using different time resolutions, obtaining different conclusions. From a performance analysis of small PV systems - $150 \mathrm{Wp}$ AC-module with $15 \mathrm{~s}$. sampling, and a $768 \mathrm{Wp}$ a-Si generator with $10 \mathrm{~s}$. sampling, respectivelyBurger and Rüther (2006) and Ransome and Funtan (2005) conclude that hourly averaging of the irradiance hides energy contribution from high irradiance conditions and recommend not to undersize inverters. However, Vijayakumar et al. (2005) find that the use of hourly data instead of 1-min data does not have a significant impact on monthly average daily tilted radiation values, despite the observed short-term variability. For these authors the effects of this variability apparently cancel when calculations are integrated over monthly periods. Finally, Boland and Dik (2001) carry out a large number of simulations using hourly data, and conclude that "there is no statistically significant difference in the results from simulation whether or not the hour-tohour stochastic component of solar radiation is included in input data set [...] [although PV system] performance could well be influenced by the integration of minute solar radiation into hourly values."

It can be shown that "despite second order effects associated to wind, spectrum, etc., energy produced by a PV grid-connected system follows a quasi-linear relation with effective irradiation falling in the generator surface" (Perpiñan et al., 2007) . Therefore, energy estimation using only mean energy values - no matter what stochastic behaviour characterise our database- leads to accurate results. Here we will use several radiation databases from different locations in Spain, with time resolutions from 1 to 10 min., to analyse the representativity of different radiation models for energy estimation.

\section{Analysis}

\subsection{Transformations applied to radiation databases}

Our hypothesis is that estimation of energy production can be adequately carried out with hourly samples of irradiance. Moreover, if some error is assumed, the use of monthly averages of daily radiation is enough for a good approximation. In order to analyse if these statements are true, we have rearranged several radiation databases in such a way that probabilistic distributions are altered, as illustrated in Fig. 1. Energy production by a PVGCS will be estimated with the new solar radiation sequences. Differences between the results will show the validity of our assumptions. The comparison between the results will clarify that energy produced by a PVGCS is mostly independent of the probabilistic distribution of the radiation. 
When measuring radiation there are two main methods: first, to use the same frequency for measuring and storing; second, to use a lower frequency for storing data than for measuring radiation. With the first method, every measured sample is stored. With the second one, each stored data is constructed with the average of several samples measured during a period. The four databases we have analysed use the first procedure. However, one of the transformations $\left(S 1 \_R A x\right)$ has been designed for simulating the second method of acquisition.

Different groups of transformations have been applied to the original databases, as summarised in Table 1. This table shows the description of each of these transformations, and some details about the size of the recorded information. It is important to mention that the column "Hours Per Day" comprises only the average value of daylength of all the days recorded for each transformation.

\subsection{Results of the transformations}

In order to compare the representativity of these transformations, we calculate the energy produced by a PV grid-connected system using the radiation sequences provided by each of them. It must be stressed that the results to be obtained are independent of the energy calculation method. We have chosen the method of statistical moments (Perpiñan et al., 2007) due to its ease of use, but the interested reader will obtain similar results with his or her preferred method. For the comparison between transformations the PV system must be characterised with parameters related mainly to the generator and inverter. We have used the system parameters extracted from a measurement campaign on a inverter of the Photocampa project (Perpiñan et al., 2003), a $351 \mathrm{kWp}$ PV grid-connected system composed on several inverters of different characteristics. Once again, the results of this comparison will not be altered if the reader carries out the calculations with parameters belonging to other commercial equipments.

Some different Spanish radiation databases have been taken as source data, whose characteristics are summarised in Table 2. In order to avoid error due to the horizontal to inclined plane transformation, calculations have been applied to horizontal radiation data. Results are provided in Tables (3) to (8) and figures (2) to (5). The original irradiation database, $G_{a, o}$, is characterised by its time resolution, $t_{0}$, that is, the sampling period of the data acquisition system. For comparison purposes, we use energy values obtained with the original database as a reference $\left(G_{a, o}\right)$. Therefore, the columns containing error values, are calculated upon this reference. For example, the annual horizontal irradiation if we consider the original database, is $G_{r e f}^{a}=\frac{t_{0}}{60} \sum_{T} G_{o}$. When we undertake the transformation $j$ with a sampling period $t_{s_{i}}$, then the elements of the new database are denoted by $G_{j, t_{i}}$, while the annual 
irradiation is calculated with $G_{j, i}^{a}=\frac{t_{s_{i}}}{60} \sum_{T} G_{j, t_{s_{i}}}$ and the error with $e_{G}^{j, i}=$ $\frac{G_{j, i}^{a}}{G_{r e f}^{a}}-1$. Similar equations quantify DC and AC energy, and their respective errors, for each transformation and sampling period. If $t_{0}=1 \mathrm{~min}$., then $t_{s_{i}} \in\{1,2,5,10,15,20,30,60\}$ min., while if $t_{0}=10$ min., then $t_{s_{i}} \in\{10,20,30,60\}$ min.

It is remarkable that this exercise tries to estimate energy produced during one especific year with radiation values corresponding to that same year. If the reader is predicting the energy to be produced in the future, these results are still valid provided the source information corresponds to mean values of radiation of a range of years, and the prediction is to be extended to an adequately long period of years.

\subsection{Discussion of results}

- The sensitivity of the estimation of $E_{a c}$ to the time resolution is very low. That is, for a same transformation there is no appreciable variations when using hourly samples instead of, for example, minute samples.

- The error due to resampling transformations $\left(S x_{-} R x\right.$ and $\left.S 1_{-} R A x\right)$ is always inferior to $1 \%$.

- Calculations with monthly average day transformations (MARx, MARAx and $M T D x$ ) provide results with errors lower than 5\%. It is remarkable that the transformation $M T D x$, which only need 12 values of monthly mean of daily radiation, is able to estimate $E_{a c}$ with errors below $3 \%$. However, the error due to calculations with only one average day per year (YADx), is too high to be acceptable.

- The differences between different time resolutions and type of transformation are less important with radiation databases of $t_{0}=10 \mathrm{~min}$ than with the one of $t_{0}=1 \mathrm{~min}$

\section{Conclusion}

Several authors have analysed the changes of the probability density function of the solar radiation with different time resolutions. Some others have approached to study the significance of these changes when produced energy calculations are attempted. We have undertaken different transformations to four Spanish databases in order to clarify the interrelationship between radiation models and produced energy estimations. Our contribution is straightforward: the complexity of a solar radiation model needed for yearly energy calculations, is very low. Time resolutions better than hourly samples do not improve significantly the result of energy estimations. Moreover, the commonly 
available set of twelve values of monthly mean of solar radiation is enough to estimate energy with errors below $3 \%$.

\section{Acknowledgements}

We appreciate the radiation data supplied by Angeles Lopez and the team of Meteogalicia, Gabriel Sala and the team of the HELIOS station at the IES, and Bernat Codina at the Universitat de Barcelona.

\section{References}

Aguiar, R. and Collares-Pereira, M. (1992). Statistical properties of hourly global radiation. Solar Energy, 48:157-167.

Assunçâo, H. F., Escobedo, J. F., and Oliveira, A. P. (2003). Modelling frequency distributions of 5 minute-averaged solar radiation indexes using beta probability functions. Theor. Appl. Climato, 75:213-224.

Boland, J. and Dik, M. (2001). The level of complexity needed for weather data in models of solar system performance. Solar Energy, 71:187-198.

Burger, B. and Rüther, R. (2006). Inverter sizing of grid-connected photovoltaic systems in the light of local solar resource distribution characteristics and temperature. Solar Energy, 80:32-45.

Collares-Pereira, M. and Rabl, A. (1979). The average distribution of solar radiation: correlations between diffuse and hemispherical and between daily and hourly insolation values. Solar Energy, 22:155-164.

Gansler, R. A., Klein, S. A., and Beckman, W. (1995). Investigation of minute solar radiation data. Solar Energy, 55:21-27.

Liu, B. Y. H. and Jordan, R. C. (1960). The interrelationship and characteristic distribution of direct, diffuse, and total solar radiation. Solar Energy, (4):1-19.

Perpiñan, O., Lorenzo, E., and Castro, M. A. (2007). On the calculation of energy produced by a PV grid-connected system. Progress in Photovoltaics: research and applications, 15(3):265 - 274.

Perpiñan, O., Pearsall, N., Mendez, L., and Eyras, R. (2003). Photocampa: design and performance of the PV system. In Photovoltaic Energy Conversion: 3rd World Conference, volume 3, pages 2302-2305.

Ransome, S. and Funtan, P. (2005). Why hourly averaged measurement data is insufficient to model PV system performance accurately. In 20th European Photovoltaic Solar Energy Conference, pages 2752-2755.

Skartveit, A. and Olseth, J. A. (1992). The probability density and autocorrelation of short-term global and beam irradiance. Solar Energy, 49:477-487. 
Suehrcke, H. and McCormick, P. G. (1988). The frequency distribution of instantaneous insolation values. Solar Energy, 40:413-422.

Tovar, J., Olmo, F., and Alados-Arboledas, L. (1998). One-minute global irradiance probability density distributions conditioned to the optical air mass. Solar Energy, 62:387-393.

Vijayakumar, G., Kummert, M., Klein, S. A., and Beckman, W. A. (2005). Analysis of short-term solar radiation data. Solar Energy, 79:495-504. 
Table 1

Different groups of transformations have been applied to each original sequence. The original irradiation database, $G_{a, o}$, is characterised by its time resolution, $t_{0}$, that is, the sampling period of the data acquisition system. If $t_{0}=1 \mathrm{~min}$., then $x \in\{1,2,5,10,15,20,30,60\}$ min., while if $t_{0}=10 \mathrm{~min}$., then $x \in$ $\{10,20,30,60\}$ min.

\begin{tabular}{|c|c|c|c|c|c|}
\hline \multirow[b]{2}{*}{ Reference } & \multirow[b]{2}{*}{ Information Form } & \multicolumn{4}{|c|}{ Recorded Information Size } \\
\hline & & $\begin{array}{l}\text { Data } \\
\text { per } \\
\text { hour }\end{array}$ & $\begin{array}{l}\text { Hours } \\
\text { per day } \\
\text { (aver- } \\
\text { age) }\end{array}$ & $\begin{array}{l}\text { Days } \\
\text { per } \\
\text { year }\end{array}$ & $\begin{array}{l}\text { Data } \\
\text { per } \\
\text { year }\end{array}$ \\
\hline$S x_{-} R x$ & $\begin{array}{l}\text { Sampled and recorded at } x \text { minute } \\
\text { intervals (being } S 1_{-} R 1 \text { the original } \\
\text { sequence) }\end{array}$ & $\frac{60}{x}$ & 12 & 365 & $\frac{262,800}{x}$ \\
\hline$S 1_{-} R A x$ & $\begin{array}{c}\text { Sampled at } 1 \text { minute intervals and } \\
\text { recorded average at } x \text { minute } \\
\text { intervals }\end{array}$ & $\frac{60}{x}$ & 12 & 365 & $\frac{262,800}{x}$ \\
\hline$M A R x$ & $\begin{array}{c}\text { Monthly average day at } x \text { minute } \\
\text { intervals using } S x_{-} R x\end{array}$ & $\frac{60}{x}$ & 12 & 12 & $\frac{8,640}{x}$ \\
\hline$M A R A x$ & $\begin{array}{c}\text { Monthly average day at } x \text { minute } \\
\text { intervals using } S 1_{-} R A x\end{array}$ & $\frac{60}{x}$ & 12 & 12 & $\frac{8,640}{x}$ \\
\hline$M T D x$ & $\begin{array}{l}\text { Monthly Typical Day at } x \text { minute } \\
\text { intervals constructed with } \\
\text { irradiance profiles given in (Liu and } \\
\text { Jordan, 1960) and (Collares-Pereira } \\
\text { and Rabl, 1979) obtaining the } \\
\text { monthly mean value of daily global } \\
\quad \text { irradiation from } S x_{-} R x\end{array}$ & - & - & 12 & 12 \\
\hline$Y A D x$ & $\begin{array}{l}\text { Yearly average day at } x \text { minute } \\
\text { intervals using } S x_{-} R x\end{array}$ & $\frac{60}{x}$ & 12 & 1 & $\frac{720}{x}$ \\
\hline
\end{tabular}

Table 2

Databases used for the comparison of radiation models

\begin{tabular}{|c|c|c|c|c|c|}
\hline Name & Location & Latitude & Longitude & $t_{0}$ & $N_{s}$ \\
\hline \hline Pedro Murias & Ribadeo (Galicia) & $43.5 \mathrm{~N}$ & $7.1 \mathrm{~W}$ & 10 & 22,683 \\
\hline Lourizan & Pontevedra (Galicia) & $42.4 \mathrm{~N}$ & $8.7 \mathrm{~W}$ & 10 & 25,361 \\
\hline Universidad Fisicas & Barcelona (Cataluña) & $41.4 \mathrm{~N}$ & $2.1 \mathrm{E}$ & 10 & 25,962 \\
\hline IES & Madrid (Madrid) & $40.4 \mathrm{~N}$ & $3.7 \mathrm{E}$ & 1 & 249,527 \\
\hline
\end{tabular}


Comparison of Histograms

for different transformations and time resolutions

MARAx O

MARX

MTDX

Sx-Rx

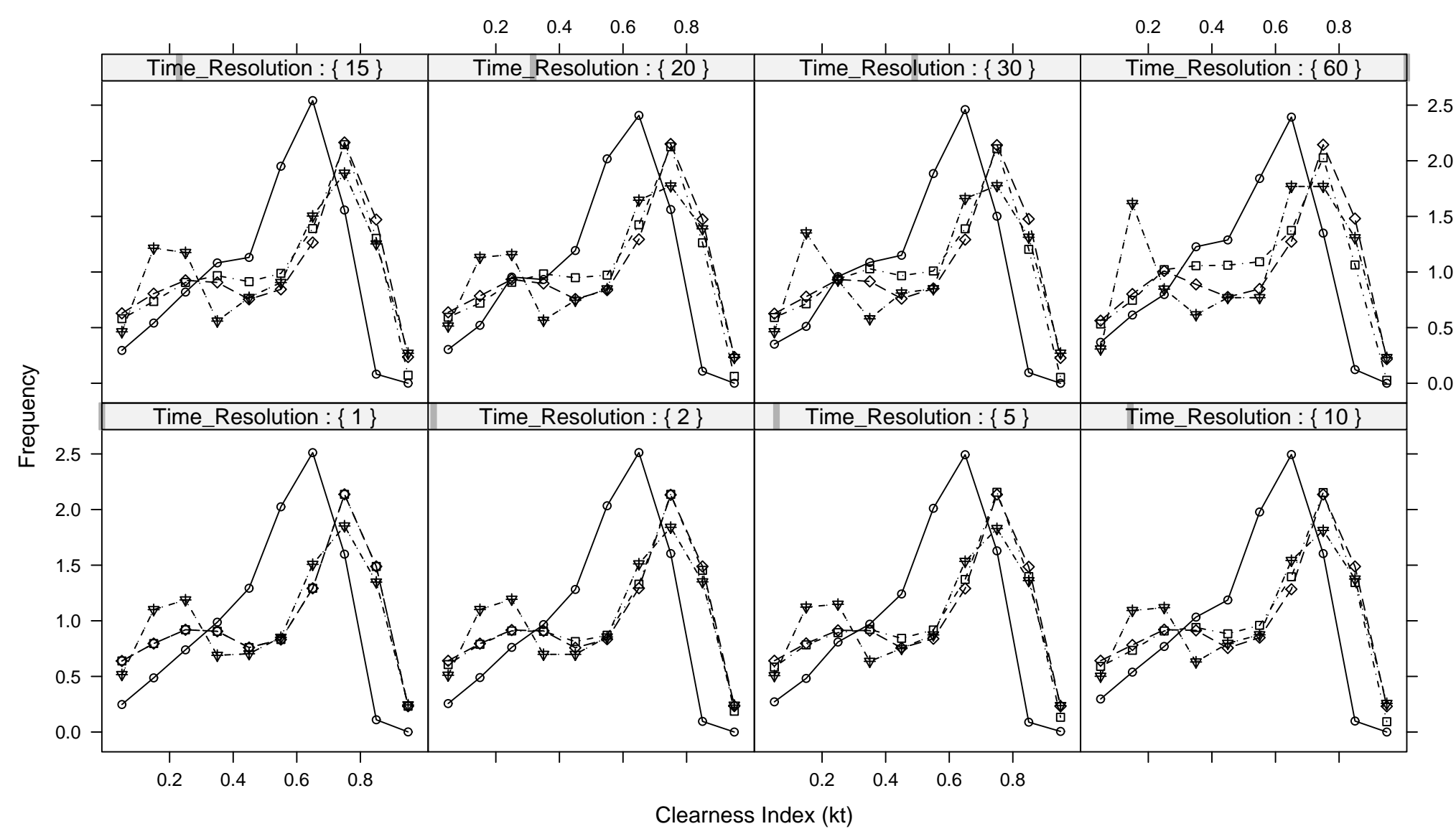

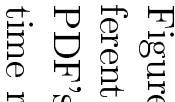

\begin{tabular}{llll}
\hline & in & 0 \\
0 & 0 & 0
\end{tabular}

象央:

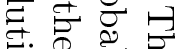

8 ㅇ․ㅇ

요웡

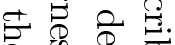

की

$+\frac{1}{4}$

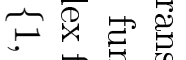

No

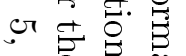

$b$ 至

国可

is

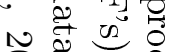

क ष्ष

比点通

요원 붕

웅.

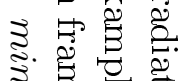

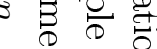

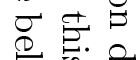

年

乘

ते

2 is

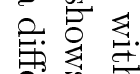

क्व

导居 
Radiation Models Comparation with IES database

MARAx

MARx

MTDx

S1_RAx
Sx_Rx

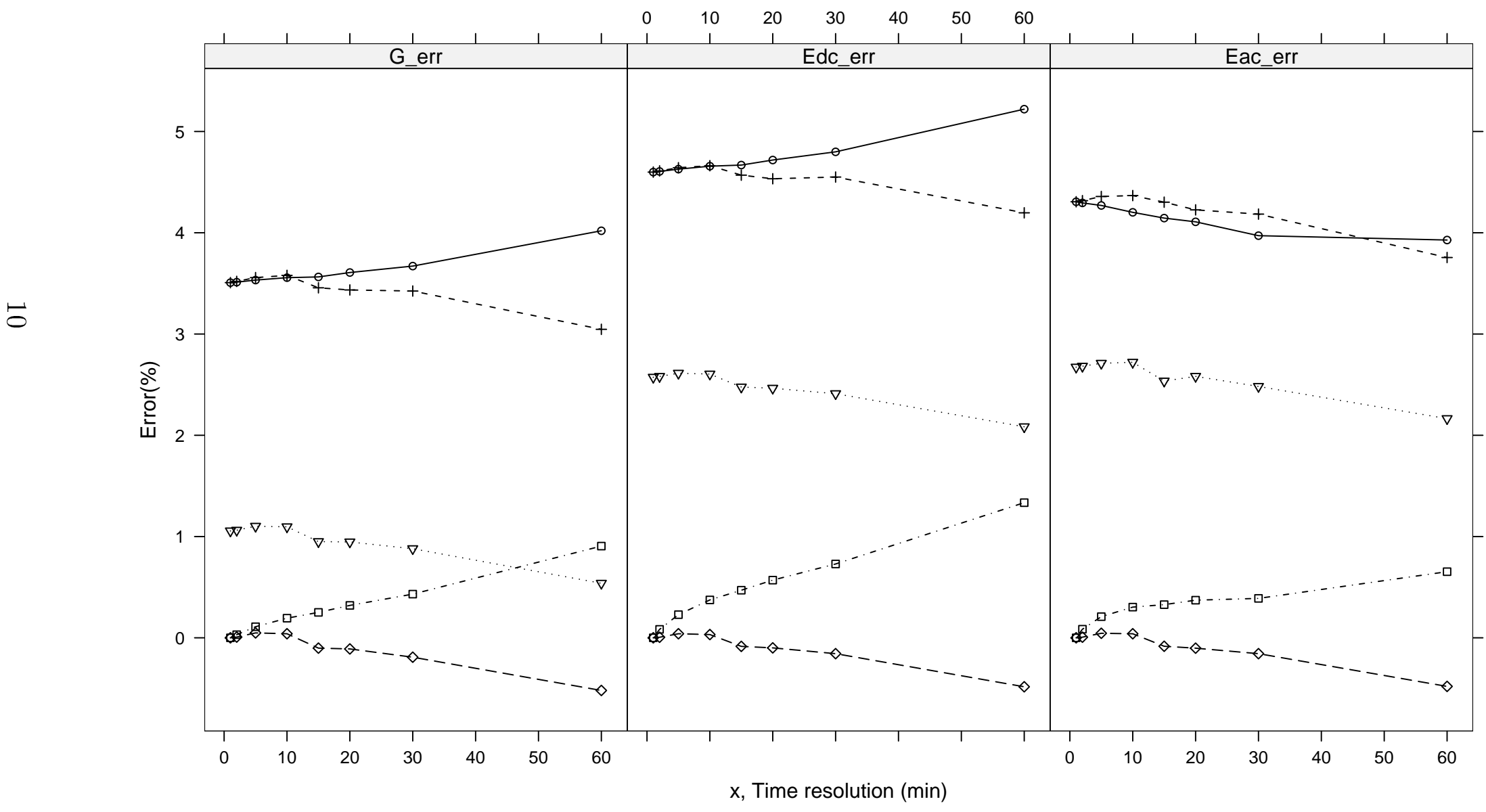




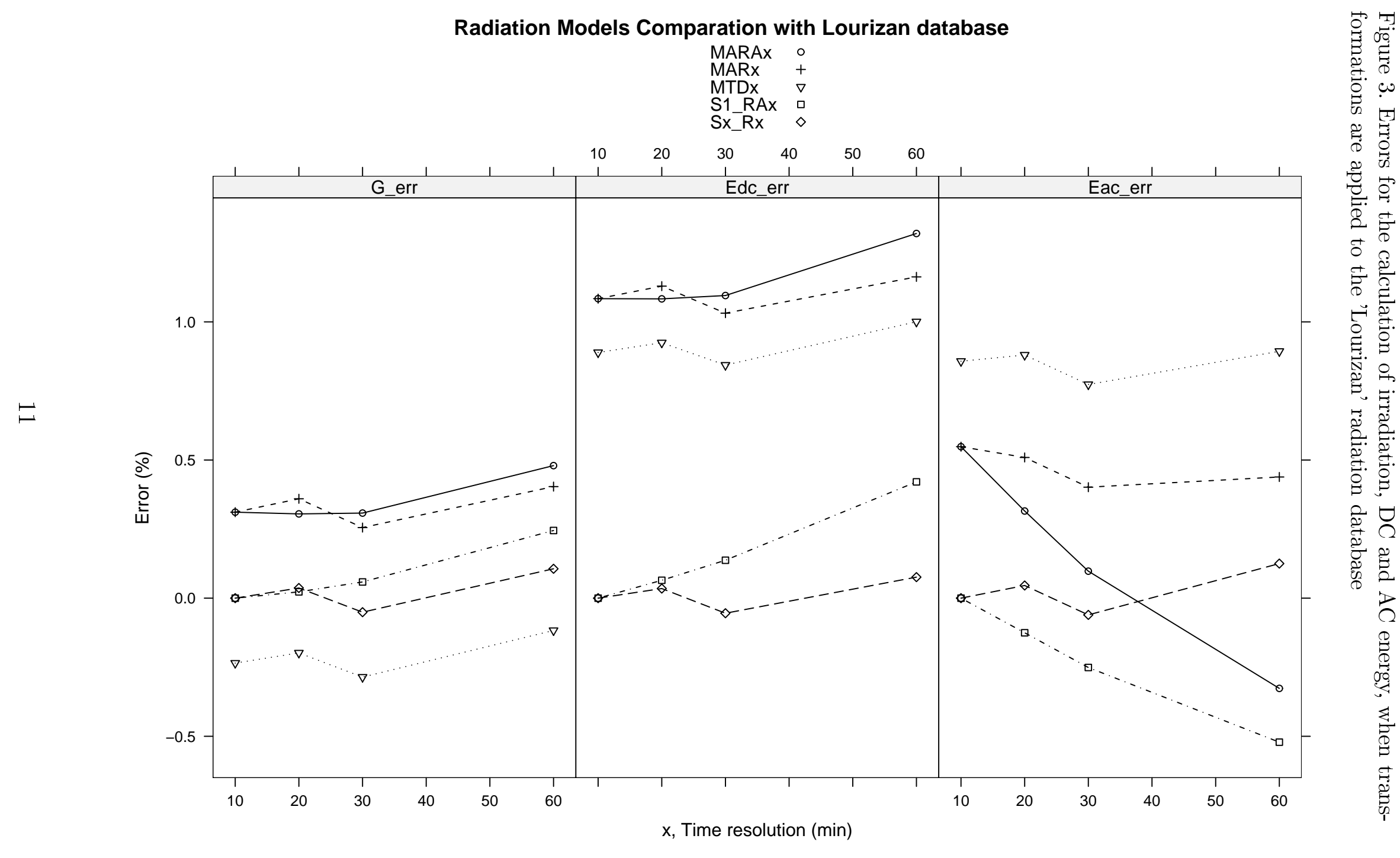




\section{Radiation Models Comparation with Barcelona database}

$$
\text { MARAx }
$$

MARX

$$
\text { S1_RAx }
$$

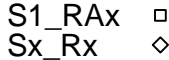

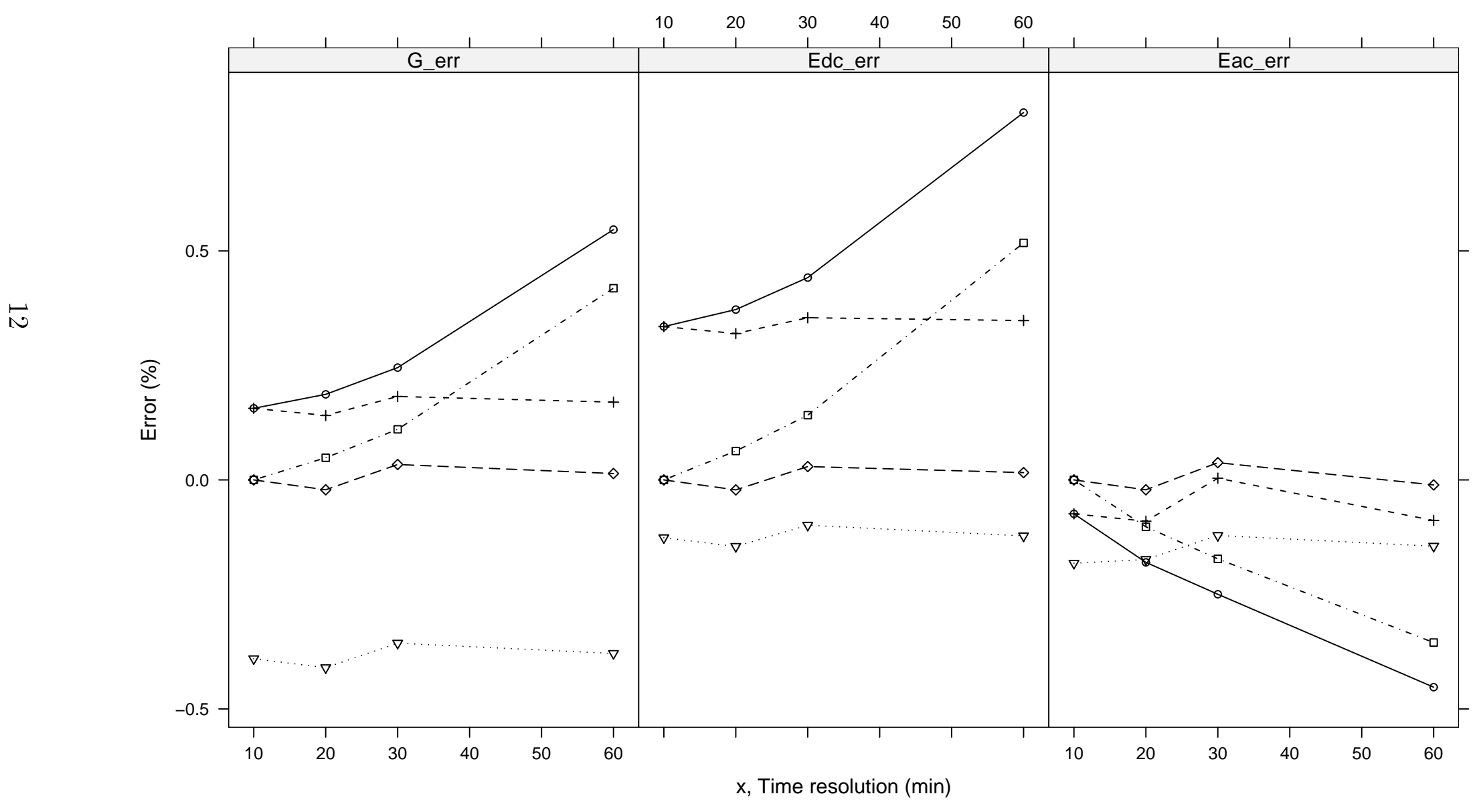

$\mathrm{x}$, Time resolution $(\mathrm{min})$ 


\section{Radiation Models Comparation with Pedro Murias database}

MARAx

MARx

MTDx

S1_RAx
Sx-Rx

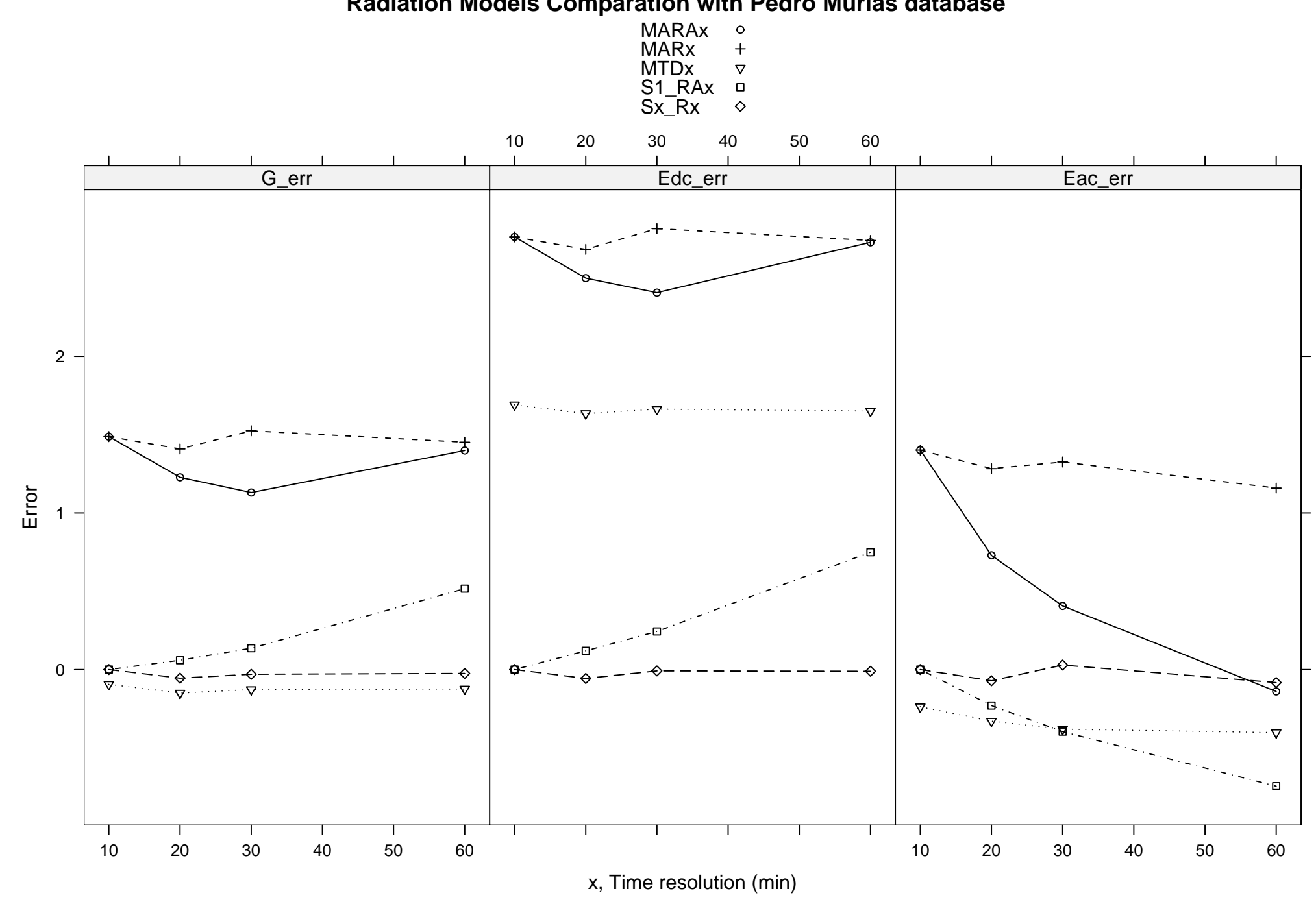


Table 3

Results of calculations when the transformation $S x_{-} R x$ is applied to the 'IES' radiation database

\begin{tabular}{|c|c|c|c|c|c|c|}
\hline $\mathrm{x}$ & $G_{a}$ & $E_{d c}$ & $E_{a c}$ & $e_{G_{a}}$ & $e_{E_{d c}}$ & $e_{E_{a c}}$ \\
\hline \hline 1 & 1742.05 & 1480.06 & 1275.66 & $0.00 \%$ & $0.00 \%$ & $0.00 \%$ \\
\hline 2 & 1742.17 & 1480.15 & 1275.74 & $0.01 \%$ & $0.01 \%$ & $0.01 \%$ \\
\hline 5 & 1742.89 & 1480.66 & 1276.23 & $0.05 \%$ & $0.04 \%$ & $0.04 \%$ \\
\hline 10 & 1742.75 & 1480.54 & 1276.17 & $0.04 \%$ & $0.03 \%$ & $0.04 \%$ \\
\hline 15 & 1740.27 & 1478.81 & 1274.59 & $-0.10 \%$ & $-0.08 \%$ & $-0.08 \%$ \\
\hline 20 & 1740.13 & 1478.59 & 1274.35 & $-0.11 \%$ & $-0.10 \%$ & $-0.10 \%$ \\
\hline 30 & 1738.71 & 1477.75 & 1273.66 & $-0.19 \%$ & $-0.16 \%$ & $-0.16 \%$ \\
\hline 60 & 1732.99 & 1472.91 & 1269.54 & $-0.52 \%$ & $-0.48 \%$ & $-0.48 \%$ \\
\hline
\end{tabular}

Table 4

Results of calculations when the transformation $S 1_{-} R A x$ is applied to the 'IES' radiation database

\begin{tabular}{|c|c|c|c|c|c|c|}
\hline $\mathrm{x}$ & $G_{a}$ & $E_{d c}$ & $E_{a c}$ & $e_{G_{a}}$ & $e_{E_{d c}}$ & $e_{E_{a c}}$ \\
\hline \hline 1 & 1742.05 & 1480.06 & 1275.66 & $0.00 \%$ & $0.00 \%$ & $0.00 \%$ \\
\hline 2 & 1742.59 & 1481.3 & 1276.74 & $0.03 \%$ & $0.08 \%$ & $0.08 \%$ \\
\hline 5 & 1743.95 & 1483.45 & 1278.33 & $0.11 \%$ & $0.23 \%$ & $0.21 \%$ \\
\hline 10 & 1745.42 & 1485.6 & 1279.53 & $0.19 \%$ & $0.37 \%$ & $0.30 \%$ \\
\hline 15 & 1746.42 & 1487.02 & 1279.84 & $0.25 \%$ & $0.47 \%$ & $0.33 \%$ \\
\hline 20 & 1747.62 & 1488.5 & 1280.4 & $0.32 \%$ & $0.57 \%$ & $0.37 \%$ \\
\hline 30 & 1749.56 & 1490.86 & 1280.62 & $0.43 \%$ & $0.73 \%$ & $0.39 \%$ \\
\hline 60 & 1757.82 & 1499.82 & 1283.99 & $0.91 \%$ & $1.33 \%$ & $0.65 \%$ \\
\hline
\end{tabular}


Table 5

Results of calculations when the transformation $M A R x$ is applied to the IES radiation database

\begin{tabular}{|c|c|c|c|c|c|c|}
\hline $\mathrm{x}$ & $G_{a}$ & $E_{d c}$ & $E_{a c}$ & $e_{G_{a}}$ & $e_{E_{d c}}$ & $e_{E_{a c}}$ \\
\hline \hline 1 & 1803.15 & 1548.13 & 1330.59 & $3.51 \%$ & $4.60 \%$ & $4.31 \%$ \\
\hline 2 & 1803.37 & 1548.31 & 1330.73 & $3.52 \%$ & $4.61 \%$ & $4.32 \%$ \\
\hline 5 & 1804.01 & 1548.77 & 1331.25 & $3.56 \%$ & $4.64 \%$ & $4.36 \%$ \\
\hline 10 & 1804.4 & 1549.07 & 1331.37 & $3.58 \%$ & $4.66 \%$ & $4.37 \%$ \\
\hline 15 & 1802.26 & 1547.69 & 1330.54 & $3.46 \%$ & $4.57 \%$ & $4.30 \%$ \\
\hline 20 & 1801.89 & 1547.16 & 1329.57 & $3.44 \%$ & $4.53 \%$ & $4.23 \%$ \\
\hline 30 & 1801.7 & 1547.41 & 1329.04 & $3.42 \%$ & $4.55 \%$ & $4.18 \%$ \\
\hline 60 & 1795.12 & 1542.18 & 1323.57 & $3.05 \%$ & $4.20 \%$ & $3.76 \%$ \\
\hline
\end{tabular}

Table 6

Results of calculations when the transformation $M A R A x$ is applied to the 'IES' radiation database

\begin{tabular}{|c|c|c|c|c|c|c|}
\hline $\mathrm{x}$ & $G_{a}$ & $E_{d c}$ & $E_{a c}$ & $e_{G_{a}}$ & $e_{E_{d c}}$ & $e_{E_{a c}}$ \\
\hline \hline 1 & 1803.15 & 1548.13 & 1330.59 & $3.51 \%$ & $4.60 \%$ & $4.31 \%$ \\
\hline 2 & 1803.23 & 1548.23 & 1330.45 & $3.51 \%$ & $4.61 \%$ & $4.29 \%$ \\
\hline 5 & 1803.59 & 1548.57 & 1330.13 & $3.53 \%$ & $4.63 \%$ & $4.27 \%$ \\
\hline 10 & 1804 & 1549 & 1329.26 & $3.56 \%$ & $4.66 \%$ & $4.20 \%$ \\
\hline 15 & 1804.13 & 1549.16 & 1328.53 & $3.56 \%$ & $4.67 \%$ & $4.14 \%$ \\
\hline 20 & 1804.89 & 1549.9 & 1328.06 & $3.61 \%$ & $4.72 \%$ & $4.11 \%$ \\
\hline 30 & 1806 & 1551.09 & 1326.32 & $3.67 \%$ & $4.80 \%$ & $3.97 \%$ \\
\hline 60 & 1812.07 & 1557.33 & 1325.77 & $4.02 \%$ & $5.22 \%$ & $3.93 \%$ \\
\hline
\end{tabular}


Table 7

Results of calculations when the transformation $M T D x$ is applied to the 'IES' radiation database

\begin{tabular}{|c|c|c|c|c|c|c|}
\hline $\mathrm{x}$ & $G_{a}$ & $E_{d c}$ & $E_{a c}$ & $e_{G_{a}}$ & $e_{E_{d c}}$ & $e_{E_{a c}}$ \\
\hline \hline 1 & 1760.43 & 1518.15 & 1309.76 & $1.06 \%$ & $2.57 \%$ & $2.67 \%$ \\
\hline 2 & 1760.55 & 1518.27 & 1309.88 & $1.06 \%$ & $2.58 \%$ & $2.68 \%$ \\
\hline 5 & 1761.24 & 1518.73 & 1310.24 & $1.10 \%$ & $2.61 \%$ & $2.71 \%$ \\
\hline 10 & 1761.14 & 1518.61 & 1310.37 & $1.10 \%$ & $2.60 \%$ & $2.72 \%$ \\
\hline 15 & 1758.6 & 1516.72 & 1308 & $0.95 \%$ & $2.48 \%$ & $2.54 \%$ \\
\hline 20 & 1758.54 & 1516.54 & 1308.6 & $0.95 \%$ & $2.46 \%$ & $2.58 \%$ \\
\hline 30 & 1757.38 & 1515.75 & 1307.33 & $0.88 \%$ & $2.41 \%$ & $2.48 \%$ \\
\hline 60 & 1751.43 & 1510.91 & 1303.27 & $0.54 \%$ & $2.08 \%$ & $2.16 \%$ \\
\hline
\end{tabular}

Table 8

Results of calculations when the transformation $Y A D x$ is applied to the 'IES' radiation database

\begin{tabular}{|c|c|c|c|c|c|c|}
\hline $\mathrm{x}$ & $G_{a}$ & $E_{d c}$ & $E_{a c}$ & $e_{G_{a}}$ & $e_{E_{d c}}$ & $e_{E_{a c}}$ \\
\hline \hline 1 & 1930.31 & 1683.78 & 1436.63 & $10.8 \%$ & $13.8 \%$ & $12.6 \%$ \\
\hline 2 & 1930.55 & 1683.95 & 1436.57 & $10.8 \%$ & $13.8 \%$ & $12.6 \%$ \\
\hline 5 & 1931.47 & 1684.7 & 1436.66 & $10.9 \%$ & $13.8 \%$ & $12.6 \%$ \\
\hline 10 & 1931.72 & 1684.96 & 1435.87 & $10.9 \%$ & $13.8 \%$ & $12.6 \%$ \\
\hline 15 & 1930.14 & 1683.86 & 1438 & $10.8 \%$ & $13.8 \%$ & $12.7 \%$ \\
\hline 20 & 1928.44 & 1682.38 & 1433.46 & $10.7 \%$ & $13.7 \%$ & $12.4 \%$ \\
\hline 30 & 1929.7 & 1683.61 & 1434.66 & $10.8 \%$ & $13.7 \%$ & $12.5 \%$ \\
\hline 60 & 1926.88 & 1681.7 & 1432.94 & $10.6 \%$ & $13.6 \%$ & $12.3 \%$ \\
\hline
\end{tabular}

